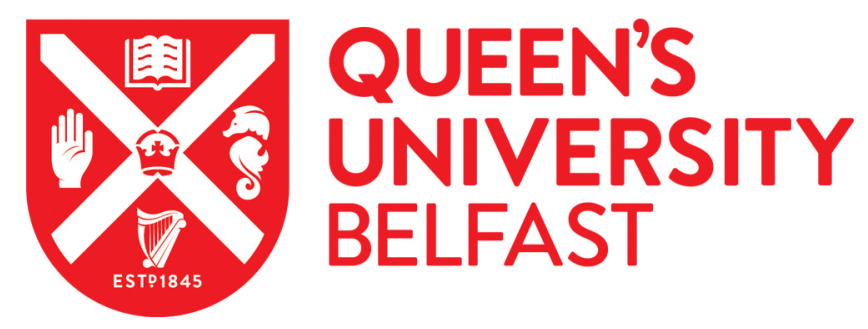

\title{
Adolescent substance use in the context of the family: a qualitative study of young people's views on parent-child attachments, parenting style and parental substance use
}

McLaughlin, A., Campbell, A., \& McColgan, M. (2016). Adolescent substance use in the context of the family: a qualitative study of young people's views on parent-child attachments, parenting style and parental substance use. Substance Use and Misuse, 1846-55. [10.1080/10826084.2016.1197941.].

http://www.tandfonline.com/doi/full/10.1080/10826084.2016.1197941 ?scroll=top\&needAccess=true

\section{Published in:}

Substance Use and Misuse

\section{Document Version:}

Peer reviewed version

Queen's University Belfast - Research Portal:

Link to publication record in Queen's University Belfast Research Portal

\author{
Publisher rights \\ (C) 2016 Informa Group plc. Set statement: This is an Accepted Manuscript of an article published by Taylor \& Francis in Substance Use and \\ Misuse on 08/09/2016, available online: http://www.tandfonline.com/doi/full/10.1080/10826084.2016.1197941?scroll=top\&needAccess=true
}

\section{General rights}

Copyright for the publications made accessible via the Queen's University Belfast Research Portal is retained by the author(s) and / or other copyright owners and it is a condition of accessing these publications that users recognise and abide by the legal requirements associated with these rights.

Take down policy

The Research Portal is Queen's institutional repository that provides access to Queen's research output. Every effort has been made to ensure that content in the Research Portal does not infringe any person's rights, or applicable UK laws. If you discover content in the Research Portal that you believe breaches copyright or violates any law, please contact openaccess@qub.ac.uk. 


\title{
Adolescent substance use in the context of the family: a qualitative study of young
}

people's views on parent-child attachments, parenting style and parental substance use

\begin{abstract}
Background: Adolescent substance use can place youth at risk of a range of poor outcomes. Few studies have attempted to explore in-depth young people’s perceptions of how familial processes and dynamics influence adolescent substance use.
\end{abstract}

Objectives: This paper aimed to explore risk and protective factors for youth substance use within the context of the family with a view to informing family based interventions.

Methods: Nine focus groups supplemented with participatory techniques were facilitated with a purposive sample of sixty-two young people (age 13-17 years) from post-primary schools across Northern Ireland. The data were transcribed verbatim and analysed using thematic analysis.

Results: Three themes emerged from the data: 1) parent-child attachments, 2) parenting style and 3) parental and sibling substance misuse. Parent-child attachment was identified as an important factor in protecting adolescents from substance use in addition to effective parenting particularly an authoritative style supplemented with parental monitoring and strong parent-child communication to encourage child disclosure. Family substance use was considered to impact on children's substance use if exposed at an early age and the harms associated with parental substance misuse were discussed in detail. Both parent and child gender differences were cross-cutting themes.

Conclusion: Parenting programmes (tailored to mothers and fathers) may benefit young people via components on authoritative styles, parental monitoring, communication, 
nurturing attachments and parent-child conflict. Youth living with more complex issues, e.g. parental substance misuse, may benefit from programmes delivered beyond the family environment e.g. school based settings.

Keywords: substance, focus group, participatory, adolescent, attachment, parenting, family 


\section{Introduction}

Adolescent substance use places youth at risk of adverse health and social outcomes impacting on their family and wider society. Adolescence is a key period for experimentation (Griffin \& Botvin, 2010) and is the developmental period of highest risk for the onset of problematic alcohol and other drug use (Thatcher \& Clark, 2008; Steinberg, 2008; Oman et al., 2004). While for many, adolescent substance use represents a transitory period of experimentation, for others, it is associated with involvement in crime and delinquency (Peleg-Oren et al., 2009; Felson, Teasdale \& Burchfield, 2008; Ellickson, Tucker \& Klein, 2003); early sexual debut and unprotected sex (Fergusson \& Lynskey, 1996; Cavazos-Rehg et al., 2010); school exclusion and academic under achievement (Balsa, Giuliano, \& French, 2011; Peleg-Oren et al., 2009; Barry, Chaney \& Chaney, 2011); and mental health problems including depression, anxiety and psychosis (Deas, 2006).

Rates of substance use among youth vary internationally: 2014’s Monitoring the Future survey of drug use and attitudes among American $8^{\text {th }}, 10^{\text {th }} \& 12^{\text {th }}$ graders reported past year use of illicit drugs at 27.2 per cent (National Institute on Drug Abuse, 2014). Results from the National Comorbidity Survey reported drug use by a larger proportion of youth (42.5\%) and drug abuse by $16.4 \%$ of US adolescents (Swendsen et al., 2012). Data from the European School Survey Project on Alcohol and other drugs (ESPAD), indicate on average twenty-one per cent of boys and fifteen per cent of girls (aged 15-16 years) have tried illicit drugs at least once in their lifetime (EMCDDA, 2012).

Evidence strongly implicates the family, peers and social contexts in adolescent substance use (Velleman et al. 2005). Currently, family and school are the primary settings for intervention (Stattin \& Kerr, 2009), however, the best approach in the prevention of 
adolescent substance use remains unclear (Peterson, 2010). Primary socialisation theory (Oetting \& Donnermeyer, 1998; Rew et al., 2013), identifies the family as one of the primary socialisation sources for young people and systematic reviews of interventions indicate that certain family based models may have some benefit (see Gates et al., 2006; Foxcroft \& Tsertsvadze, 2011). The family may prevent and intervene with substance use, through inducing risk and/or promoting protection and resilience (Velleman et al., 2005). Evidence indicates authoritative parenting styles (Calafat et al., 2014; Adalbjarnardottir \& Hafsteinsson, 2001; Baumrind, 1991), positive parent-child attachments (Velleman, 2009; van der Vorst et al., 2006) and parental monitoring can protect young people from substance use (Higgins et al., 2013; Fallu et al., 2010; Frisher et al., 2007). One central risk factor within families is the role that social learning processes play in modelling the behaviours and attitudes regarding substance use (Griffin \& Botvin, 2010) in addition to providing opportunities to gain access to substances (Chuang et al., 2009). Evidence suggests exposure to parental substance misuse can place adolescents at risk of involvement with drugs and alcohol (Chuang et al., 2009; Hooper et al., 2012; Mares et al., 2011; Muller \& Kuntsche, 2011).

Quantitative data have provided valuable evidence for the development of interventions. However, they cannot explore young people’s lived experiences in depth or in context because they rely on relatively simple quantitative measures (Fletcher et al., 2009). Qualitative methods allow us to achieve a deeper understanding of the social processes underlying behaviour (Morse \& Richards, 2002). Some studies have elicited accounts from parents. For example, Gilligan \& Kypri (2012) explored the experiences and attitudes of parents of adolescents in relation to parental behaviour and approaches used to reduce drinking among adolescents. Others such as Jacob et al. (2015) interviewed young people 
(aged 18-20 years) on their alcohol use history and family reactions, reporting parental attitudes, behaviours and the nature of communication were critical factors. Few qualitative studies, however, have explored adolescent perceptions of how family processes or dynamics protect or place young people at risk of substance use. Those which have used adolescent samples, focused on generic risk and protective factors, motivations for and functions of substance use. Patrick et al. (2010) explored reasons for using substances and themes included enhancement, negative states, social and aversive social motivations. Alhyas et al. (2015) drawing on a sample of 41 adolescents, reported parent-adolescent relationship, peer pressure, accessibility and religiosity influenced substance use. Peterson (2010) reported use of drugs and alcohol was normalised by schools, community and family and positive adult role models deter use. Highet (2005) interviewed fifty-nine 13-15 year olds, concluding supporting parents openly to discuss their children's cannabis use before it becomes problematic is an important step in helping to reduce harm. Hurt et al. (2013) underscored the importance of caregivers practicing vigilant monitoring to keep adolescents from experimenting with alcohol. This study, underpinned by primary socialisation theory (Oetting \& Donnermeyer, 1998) and social learning theory (Bandura, 1977), aims to contribute to the extant knowledge base by drawing on in-depth discussions with a sample of adolescents (aged 13-17 years) to provide insight into youth perceptions of the mechanisms by which family processes protect or place youth at risk of substance use, with a view to informing family based interventions.

\section{Methods}

\section{Participatory techniques}

Focus groups can be a particularly effective method of data collection with young people in gaining insight into adolescent experiences, attitudes and perceptions (Peterson-Sweeney, 
2005). In tandem with focus groups, the study utilised participatory methods, in line with Article 12 of the United Nations Convention on the Rights of the Child (United Nations, 1989) which states children and young people have a right to have a say in issues that affect their lives. Participatory methods facilitate the process of knowledge production, as opposed to knowledge ‘gathering’ (e.g. surveys) (Veale, 2005). A ‘workshop style methodology’ (Veale, 2005) or ‘participatory focus group’ (Schubotz \& Sinclair, 2006) was applied consisting of a focus group supplemented with a poster making exercise (whereby topics were ranked in order of importance), a creative method serving as a constructivist tool to assist participants in describing their experiences and give meaning to them (Veale, 2005). The method helped to maintain concentration and interest throughout (Greene \& Hogan, 2005) and prompted further discussion of themes via reaching consensus. The methods created a safe peer environment (Mauthner, 1997), redressed the power imbalance that can exist in one-to-one interviews (Hennessy \& Heary, 2005) and acknowledged the participants as the expert (Levine \& Zimmerman, 1996).

\section{Participants}

Nine post-primary schools across Northern Ireland were selected to take part in the study encompassing variations in school location (urban, intermediate and rural) and school level characteristics (co-educational and single sex) which may determine experiences of exposure to substance use. Schools were selected across three education and library board (ELB) areas: the Western (WELB), North Eastern (NEELB) and Belfast (BELB) library board areas. Three schools were selected per board area providing a sample of four grammar and five secondary schools. To account for the structure of the education system in Northern Ireland the sample included a mix of controlled ( $n=4)$, Catholic maintained $(n=4)$ and voluntary $(n=1)$ schools. The majority of participants attended a co-educational school (n=28) (girl's school, n=21; 
boy's school, n=13). Participants were selected using purposive sampling on the basis they could provide the necessary data for the study (Sarantakos, 2001), reflecting variations in age and gender (Table 1). We did not collect information on socio-economic status from participants. However, we did elicit the multiple deprivation measure (MDM) score at Super Output Area (SOA) level, based on the school postcode using the Northern Ireland Multiple Deprivation Measure 2010 (NISRA, 2010) (whereby eight hundred and ninety SOA's in Northern Ireland are ranked from 1=most deprived to $890=$ least deprived). Four school postcodes were ranked in the 1-300 range; three school postcodes in the 301-600 range and two school postcodes were ranked in the 601-890 range. A gatekeeper at each school invited students to participate in the workshops. Sixty-two students participated in the study (range= 13-17 years; mean= 15 years), the majority of whom were female $(n=36)$ (Table 1$)$.

**Table 1 here**

In keeping with recommendations for group work with children and young people (Scott, 2000; Krueger \& Casey, 2000) a maximum of eight students were invited with an age range of no more than two years per group (Table 2) helping to avoid imbalances in group dynamics due to large age discrepancies (Greene \& Hogan, 2005).

**Table 2 here**

\section{Data collection}

The study was approved by the Office for Research Ethics Committees Northern Ireland (ORECNI). Written consent was obtained from participants and a guardian, one week prior to data collection. Participants were informed they were contributing to a study on the influence 
of the family on adolescent substance use (drugs or volatile substances). A brief demographic sheet (age, gender) was completed by each participant and a topic guide facilitated the discussion (loosely structured around themes which emerged from the international literature). Materials were provided for the poster ranking exercises. Consent to digitally record discussions was granted and participants were informed that only the researcher would have access to the recordings. All nine focus groups were facilitated by the lead researcher (AMcL). Field notes were taken during and at the end of the workshops. Prior to each focus group, the right to withdraw from the research was stressed, confidentiality and anonymity were assured, ground rules were discussed and participants were given the opportunity to ask questions. Each group lasted approximately 45 minutes to 1 hour. During the discussion, participants were encouraged to write the key 'family' factors which influence a young person's substance use on comment cards. Towards the end of the discussion, participants were requested to reach a consensus and rank each factor in order of importance or 'greatest' influence by pasting the comment cards onto a poster, whereby the most important factors were placed at the top and the least important placed at the bottom of the poster. This method assisted in generating further debate and eliciting the reasons for the selection of certain factors.

\section{Data analysis}

Discussions were transcribed verbatim with descriptors (age, gender) assigned to quotes. The data were analysed using thematic content analysis, facilitated by QSR NVivo. The data were scrutinised, condensed and simplified, a process described by Miles and Huberman (1984) as 'data reduction.' Field notes (and group posters) aided the coding of the data and the identification of themes. 


\section{Findings}

Three thematic clusters emerged from the data offering insight into youth perceptions on how family processes can protect or place a young person at risk of substance use: parent-child attachment, parenting style and parent and sibling substance use.

\section{Parent-child attachment}

Participants identified parent-child attachment as a major theme in protecting adolescents from substance use. While many acknowledged - 'there's probably plenty of people that come from a loving family but still take drugs (Female, 16), the majority reported 'if it's good (the relationship), you're less likely to take drugs (Female, 14). Factors which contributed towards positive parent-child attachments were outlined including spending quality time together and effective communication (both parent and child) and listening skills. Participants suggested spending time together may help a parent to identify or monitor any changes in the child's behaviour or develop trust which may lead to child disclosure of substance use (and early intervention).

Some people don't spend time with their parents really. They go into the house and just go straight to their room and they (the parents) don't be there, so they don't notice if there’s anything wrong with them (Female, 15)

However, it was acknowledged that it may not be possible to spend time together as a child gets older, as many teenagers spend less time with their parents and increased time with their peer group. Nonetheless, strong parent child-relations were reported as effective in mediating any negative effects of the peer group. 
'If you have a good relationship with your parents then you'll know what's right and wrong. But if you don’t, then with friends, you don’t know whether what they're doing is right or wrong' (Male, 14)

Conversely, the impact of substance use on attachments was also discussed, particularly in the event of disclosure or a parent's discovery of child substance use. Participants reported young people may be afraid of the effect it might have on the quality of the relationship with the parents; they may feel guilty about upsetting the parent and there’s the possibility of being disciplined.

If you get on well with your parents then you're going to feel really guilty about doing anything that will upset them (Female, 15)

There was a general consensus that girls tend to have better relationships with mothers and are more willing to take their advice from them, compared to their fathers, due to feeling embarrassed or awkward about the sensitive nature of the topic. They also discussed disclosing information to mothers on the condition of not passing on information to their father, due to concerns around being disciplined rather than supported.

Like, you can talk to your mum about like girly things but like, if it was just your Dad, I don’t think, I couldn’t actually tell my dad any of my problems. I’d just be sat there like, hiya. I dunno, you can tell your mum all the wee girly things and stuff but you couldn't, I couldn’t talk to my dad about any of the problems I have. I just wouldn’t know where to start. (Female, 16) 
I know it's a bit of a stereotype but I think it's easier for teenage girls to get on with their mum than teenage boys because you can talk to your mum about stuff whereas boys, they don’t want to. They look up to their friends but they won't talk to their parents (Female, 15)

In households characterised by poor parent-child and parent-parent relations (parental conflict), participants suggested young people may engage in substance use to aggravate the caregiver, seek attention or simply because it's unlikely to make any difference to their relationship.

\section{Parenting style}

Many of the participants reported that a parent's style of parenting can influence their child's substance use. Teenagers were deemed more likely to engage in substance use in households where parents withheld affection, were aggressive, strict, controlling and abusive, or considered hard to please; and in households where there were high levels of parental stress. Participants suggested substance use may help to alleviate feelings of failure, depression or loneliness or; it may be an escape mechanism or form of rebellion.

It might not be like to escape and get high or whatever. It could just be, well screw what they think. I'm just doing what I want now. They're just breaking free kind of thing (Female, 16)

Adolescents were considered less likely to use substances when parents were dedicated, loving, caring, supportive and trustworthy and; when they granted autonomy or trusted their 
children. Participants indicated low parental monitoring may place youth at risk of the influence of the peer group.

If they're allowed to run, like, anywhere at any time, then they would probably get involved with the wrong sorts of people (Female, 14)

If the parents are too lenient, they're most likely to get into a bad crowd (Male, 13)

Some participants suggested that young people from single parent families may have more opportunities to engage in substance use, for example, while their parent is at work: parental support, monitoring and discipline were highlighted as important (by both the present and absent parent) in protecting these children from substance use. However, most argued it doesn’t matter how many parents are present in the home.

They might be able to do more things like get out more and then be more prone to drugs (Female, 13)

While variations were acknowledged across households, participants generally described fathers as being strict, over protective (especially of daughters) and the primary disciplinarian while mothers were considered to be understanding, protective of their children, emotional or sensitive and open to discussion or encouraging child disclosure. Participants also raised other factors which may influence parenting including: the child's place among siblings; the care giver's psychological or physical health; and the child's peer group. 
parent's with their first kid, ... they stand up to them and they don't exactly let them out too often compared to the youngest child of the house (Male, 15)

When it comes to the youngest child, they're not as strict (Male 15)

Participants made a number of suggestions for parents which may protect their child from substance use, many of which were in line with an authoritative style of parenting (Baumrind, 1967, 1971). Suggestions included talking and relating to the child; using effective monitoring while granting autonomy; permitting the child to learn from their mistakes; providing safe boundaries; sharing feelings; nurturing confidence and child disclosure; providing and/or seeking support for the child, where necessary; not overreacting or involving the child's friends in arguments and; understanding that adolescence is a period of experimentation. Careful consideration of use of discipline was suggested, that is, while it can be effective, it may not always be so. Ideally, parents could 'try to get you help, rather than just ground you’ (Female, 16).

They have to be halfway between; they can’t be too lenient, they can’t be too strict. They have to talk right to their kids and they have to offer them support (Female, 17) My parents, they don't want me getting drugs or smoking or anything but they don't mind drinking and stuff. They don't mind me doing it as long as I'm safe, like, as long as I'm not going around the streets or something........ I don't know it's just like you can see what they're trying to- they're not being too lenient and they don't want me home really late or anything so (Female, 16) 
Like my parents would use reverse psychology on me. They're like yeah you can go out and drink which makes me feel like I don't want to go out and drink so and even though I know they're using it on me. It still works. Because they're saying to do it you're just like ‘No I don’t want to.' Ah, it’s, I don’t know. It’s so weird. I don’t want to like upset them or anything and then I'll soon. They're acting as if it's alright you know. It's ok which kind of like takes the edge off actually doing it (Female, 16)

\section{Parent and sibling substance use}

Almost half the sample reported that parental substance misuse would influence a young person's use of substances. The 'hidden' nature of parental substance misuse was discussed alongside child outcomes including neglect, bullying, abuse, emotional difficulties or depression, feelings of stress, difficulties in coping and the adoption of maladaptive coping techniques.

No one really knows what goes on behind closed doors really. But families do fall apart over drugs (Female, 14)

Participants described how the impact on child substance use outcomes may vary according to age of exposure. Early exposure was viewed as more damaging as a child may view the carer's substance use as the norm in line with social learning theories (See Bandura, 1977): 'you might learn from what you see' (Male, 14) and; due to non-exposure to other environments.

I just think, growing up with that, I don’t think it’s actually the family that's encouraging but it's just growing up seeing that. I mean if you're watching your own mother do that (take drugs), you're not 'gonna think its wrong (Female, 15) 
Well if they only started using them, like they'd notice the parents would have changed and (if) they were always like that then they would just think that it was normal (Male, 14)

The impact of exposure to parental substance misuse during adolescence may be buffered by drugs education in school. Participants reported that schools can provide an opportunity for a child to seek support for themselves or their carer (via signposting to services), equipping them with the knowledge to identify changes in the parents behaviour (e.g. when drinking or not drinking, inside and outside the home) which may indicate substance abuse.

Maybe they’ve been in school and listened to drug chats and seen the effects (Male, 15)

Well if you're looking at it all your life you're going to be thinking it's alright. Whereas if it's when you are thirteen or fourteen, you'll have already got it through school and stuff that drugs are bad. That they're not worth taking so you're not going to (Female, 16)

They also reported that parental substance use may lead to ease of access to substances; children may model the parent's behaviour or; they may use the parent’s behaviour as a rationale for their own substance use. They may also simply view substance use as enjoyable experience.

They can get their hands on drugs real easily if their parents have a stash of drugs somewhere in the house; they can just go up and take some and their parents probably wouldn't notice (Female, 16) 
I know a guy whose dad smokes cannabis and he thinks it's all brilliant and he goes and steals some from his dad and all. He thinks it’s such a good thing. His dad's given it to his friends before (Female, 14)

The impact on family dynamics was also discussed including parental attitudes and impaired parenting.

See if the parents are taking it though-they obviously don't think it's a bad thing.

They're not going to care whether their children take it (Female, 14)

Abstinence was commonly reported among those peers who lived with parental substance misuse and reasons included viewing first hand, the negative effect on the parent; witnessing the stress it placed on other family members; having to take on caring roles for younger siblings and; not wanting to become like the parent.

I know one particular person that doesn't follow their mum or dads footsteps because they’ve seen too much of it. They just don't see the point in doing it (Female, 15)

They've seen what it does to the family and you'd have to grow up around it and they wouldn't want to do the same things themselves (Female, 15)

They also discussed how peers were resilient, engaging in sports and other activities, outside the home environment.

I know like this guy, his mum, (I don’t know if she still is) but she was an alcoholic and he doesn't touch drink or drugs or smoke or anything at all, literally and he’s really into sports as well so he thinks it influences him and like he's running and (at) 
rugby and stuff and he never touches, like even in celebrations he'll never touch a drink. He’ll never drink at all because of his mum (Female, 16)

Over half of the participants reported siblings are likely to influence a young person's substance use. Sibling substance use was considered to influence family dynamics by placing stress on the parents, who subsequently, may rely on younger siblings for support. Non-using siblings may feel neglected due to attention focused on the substance user. Recreational drug use was not viewed as likely to impact on the family compared to an addiction which placed financial and emotional strain on family members. Participants indicated that older brothers and siblings of a similar age in particular, were influential in adolescent substance use as they are role models and may introduce drugs and supply substances to their siblings. Others argued they can protect younger siblings from drug use (particularly if they have experimented themselves).

If your brothers sitting in the house by himself and he has no one to smoke his blow with then he might ask you cause he didn’t want to be by himself in case he got freaked out or something. And the next day he might tell you to get away 'cause he has his friends down (Female, 13)

My brother wouldn't let me take it 'cause he knows (the effects) (Female, 13)

\section{Discussion}

This study, using a qualitative approach, contributes to our understanding of adolescent perspectives on the mechanisms by which family processes protect or place young people at risk of substance use. It is important to acknowledge that family influence does not occur in a vacuum: clearly there are other determinants on drug and alcohol use and misuse, including 
intra-personal factors, peer influence, and wider-community and environmental-factors such as the media, advertising, availability and environmental deprivation (Velleman, Templeton \& Copello, 2005). Although peers are a central influence on young people’s attitudes and behaviours, they do not negate the influence of parents, particularly where the parent-child relationship is a positive one (Sherriff et al., 2008). While many studies have identified the links between familial influences including parent-child attachment, parenting style and familial substance misuse and adolescent substance use (Calafat et al., 2014; Velleman, 2009; Fallu et al., 2010); few have attempted to elicit detailed accounts of young people’s perceptions of these processes. Understanding the interplay between family processes and youth substance use, can assist in paving the way for practical solutions to encourage appropriate sites and methods of intervention, to prevent or reduce the harm associated with adolescent substance use.

In family settings, universal prevention (for alcohol misuse) typically takes the form of supporting the development of parenting skills including parental support, nurturing behaviours, establishing clear boundaries or rules and parental monitoring (Foxcroft \& Tsertsvadze, 2011). A systematic review by Gates et al. (2006) reported that three of numerous family interventions reviewed-Focus on Families, Iowa Strengthening Families Program (SFP) and Preparing for the Drug-Free Years may be beneficial in preventing cannabis use. Another systematic review by Karki et al. (2012) indicated that family-based interventions have significant outcomes for substance use among adolescents. Velleman (2009) reports programmes that work with parents need to equip parents with three sorts of skills: parenting skills, substance-related skills and confidence skills. 
In line with the extant literature (see Stephenson et al., 2005), participants discussed their support for the links between effective parenting and a lower risk of substance use among young people. Our findings indicate that parenting programmes (targeting parents of teenagers) should educate parents on authoritative styles of parenting, parental monitoring and effective strategies to implement these in the home (e.g. granting autonomy, setting safe boundaries or limits on what's acceptable for their child to explore, permitting the child to learn from their mistakes, discuss outcomes, nurturing confidence, supporting their child). Components on monitoring, in particular, could highlight the importance of identifying changes in child behaviour, encouraging child disclosure and mitigating the influence of the peer group. Parents may also benefit from discussions around how they parent their child (e.g. adapting styles of parenting based on child temperament or the child's placement among siblings).

Our findings indicate positive attachments or relationships between parent and child may protect young people from substance use in line with previous studies (Velleman, 2009; van der Vorst et al., 2006). Parenting interventions to prevent or reduce teenage substance use should contain components on parent-child attachment, educating parents on the importance of regular spending quality time with their children, to offset any potential negative effects of the peer group. This may be particularly important as they get older and spend more time alone studying. Taking time to have family meals together may provide opportunities for discussion. Family based interventions could also contain components on effective communication: talking, listening and relating to children and the importance of sharing information or feelings. Parents could also be educated on the impact of the peer group as the child gets older and provided with information on how best to protect them. 
In line with Velleman’s (2009) suggestions, parenting programmes could also educate parents on how to cope or deal with the discovery/disclosure of child substance use, advising on appropriate or effective methods of discipline (which may vary according to the child). Components on substance use could assist parents in how best to broach the subject or deal with conflict which may result. Suggestions included support seeking and signposting to relevant organisations, not over-reacting and not involving the friends in discussions. Parenting programmes may also benefit from sessions on adolescent development highlighting the physical and hormonal changes which occur and the impact these changes have on involvement in risk taking behaviour i.e. adolescence as a period of experimentation. Participants discussed the parent's gender and the impact this had on relationships and dynamics between parent and child. It is likely that parenting programmes may benefit by addressing these gender differences. Parenting programmes targeting fathers specifically, could discuss some of the stereotypical gender roles, as perceived by many of the young people in this study. Programmes could provide fathers with the skills required to communicate with and support their children, highlight the importance of fathers in children's lives and educate them on different strategies for talking to teenage boys and girls and dealing with substance use. A recent review by Panter-Brick et al. (2014) highlighted the lack of engagement with fathers in parenting programmes despite evidence of their impact on children and mothers.

Opinions around parental substance misuse were divided whereby it may lead to either substance use or abstinence among youth, in line with the extant literature (Mares et al., 2011; Muller \& Kuntsche, 2011). Parenting interventions could contain components on parental substance misuse (or more generically, factors that can impact on parenting such as mental and physical health and stress) and educate parents on the effect of substance use on 
child outcomes such as child neglect, emotional difficulties and maladaptive coping strategies such as substance use. They could also educate parents on the impact of substance use on the wider family and dynamics (e.g. parental attitudes, impaired parenting). However, interventions to protect children living with parental substance use, may be best delivered in school settings which can provide support for these youth and equip them with the knowledge to identify changes in parent's behaviour. The findings, particularly perceptions focusing on negative outcomes from early exposure, highlight the importance of school based interventions in targeting all youth exposed to parental substance misuse to reduce their own risk of developing substance use problems. School based interventions are ideal to signpost children to relevant services which build resilience, provide knowledge on substance use, coping skills or strategies (e.g. sports, activities outside the home) to deal with stress and emotional problems in order to avoid maladaptive coping strategies. Interventions targeting children of substance misusers are in their infancy, however, there has been a rise in the development of services in recent years (Templeton et al., 2010).

A number of study limitations must be acknowledged. Data were collected from a school based sample and we did not elicit information regarding the participant's lifetime substance use. However, discussions using the ‘third person' and 'hypothetical scenarios' may be suggestive of personal insights (Hill, 2013). Participants were purposively selected by a liaison teacher and the participant's experience of substance use may have influenced the selection process. Furthermore, we acknowledge that as an agent of the school, the liaison teacher may have had a vested interest in the selection process and the subsequent representation of their school that was put forward. Permission for a focus group with 11-12 year olds was not provided in the schools. This may have been due to the sensitive nature of the research topic; schools may not have wanted younger students to participate or the 
teachers may have simply chosen older students as they were more knowledgeable on the topic (or they may have thought the topic was not relevant to younger children). Focus groups were facilitated in school settings and some locations (such as schools) represent places where young people are subordinate to adults and may have certain rules about a topic (Krueger \& Casey, 2000). This may have influenced participant's willingness to talk openly about substance use. Future studies could ask young people about their own and their parents substance use to explore protective factors. The use of neutral locations and peer researchers are recommended.

In conclusion, this study contributes to our understanding of adolescent views via detailed accounts of the mechanisms by which family processes protect or place youth at risk of substance use, as opposed to relying on relatively simple quantitative measures (Fletcher et al., 2009). The qualitative methods employed provided an opportunity to elicit recommendations from teenagers for parents/carers on effective strategies which may be implemented as part of their parenting e.g. family meals, not involving friends in discussions around substance use, so that future interventions are informed from a youth perspective. The findings highlight a role for parenting programmes in providing parents with the skills to protect their youth from harm associated with substance misuse. Youth affected by parental substance use may be best supported by school based interventions.

\section{Declaration of interest:}

The authors report no conflicts of interest. The authors alone are responsible for the content and writing of the paper. 


\section{References}

Adalbjarnardottir, S. \& Hafsteinsson, L.G. (2001). Adolescents Perceived Parenting Styles and Their Substance Use: Concurrent and Longitudinal Analyses. Journal of Research on Adolescence, 11(4), 401-423.

Alhyas, L., Al Ozaibi, N., Elarabi, H., El-Kashef, A., Wanigaratne, S., Almarzouqi, A., Alhosani, A. \& Al Ghaferi, H. (2015). Adolescents' perception of substance use and factors influencing its use: a qualitative study in Abu Dhabi. Journal of the Royal Society of Medicine Open, 6 (2), doi:10.1177/2054270414567167.

Balsa, A.I., Giuliano, L.M., French, M.T. (2011). The effects of alcohol use on academic achievement in high school. Economics of Education Review, 30 (1), 1-15.

Bandura A. (1977). Social Learning Theory. Englewood Cliffs: Prentice-Hall.

Barry, A.E., Chaney, B. \& Chaney, J.D. (2011). The Impact of Truant and Alcohol-Related Behavior on Educational Aspirations: A Study of US High School Seniors. The Journal of School Health, 81 (8), 485-492.

Baumrind, D. (1967). Child-care practices anteceding three patterns of preschool behaviour. Genetic Psychology Monographs, 75, 43-88.

Baumrind, D. (1971). Current patterns of parental authority. Developmental Psychology, 4 (Monograph 1), 1-103. 
Baumrind, (1991). “The Influence of Parenting Style on Adolescent Competence and Substance Abuse.” Journal of Early Adolescence, 11 (1), 56-95.

Boys, A., Marsden, J. \& Strang, J. (2001). Understanding reasons for drug use amongst young people: a functional perspective. Health Education Research, 16(4), 457-469.

Calafat, A., Garcia, F., Juan, M., Becona, E. \& Fernandez-Hermida, J.R. (2014). Which parenting style is more protective against adolescent substance use? Evidence within the European context. Drug \& Alcohol Dependence, 138: 185-92.

Cavazos-Rehg, P.A., Spitznagel, E.L., Bucholz, K.K., Nurnberger, J., Edenberg, H.J., Kramer, J.R., Kuperman, S., Hesselbrock, V., Bierut, L.J. (2010). Predictors of Sexual Debut at Age 16 or Younger. Archives of Sexual Behaviour, 39(3), 664-673.

Chuang, Y-C., Ennett, S.T., Bauman, K.E. \& Foshee, V.A. (2009). Relationships of Adolescents’ Perceptions of Parental and Peer Behaviors with Cigarette and Alcohol Use in Different Neighborhood Contexts. Journal of Youth and Adolescence, 38.10, 1388-98.

Deas, D. (2006). Adolescent substance abuse and psychiatric comorbidities. Journal of Clinical Psychiatry, 67, Suppl 7, 18-23.

Ellickson, P.L. Tucker, J.S., Klein, D.J. (2003). Ten-year prospective study of public health problems associated with early drinking. Pediatrics, 111: 949-55. 
European Monitoring Centre for Drugs and Drug Addiction (2012). Summary 2011 ESPAD Report: Substance use among students in 36 European Countries. Lisbon, Portugal: EMCDDA.

Fallu, J.S., Janosz, M., Briere, F.N., Descheneaux, A., Vitaro, F. \& Tremblay, R.E. (2010). Preventing disruptive boys from becoming heavy substance users during adolescence: a longitudinal study of familial and peer-related protective factors. Addictive Behaviors, 35(12), 1074-82.

Felson, R.B., Teasdale, B. \& Burchfield, K.B. (2008). The influence of being under the influence: Alcohol effects on adolescent violence. Journal of Research in Crime and Delinquency, 45 (2), 119-141.

Fergusson, D.M. \& Lynskey, M.T. (1996). Alcohol misuse and adolescent sexual behaviors and risk taking. Pediatrics, 98:91-6.

Fletcher, A., Bonell, C., Sorhaindo, A. \& Strange, V. (2009). How Might Schools Influence Young People’s Drug Use? Development of Theory From Qualitative Case-Study Research. Journal of Adolescent Health, 45, 126-132.

Foxcroft, D.R. \& Tsertsvadze, A. (2011). Universal family-based prevention programs for alcohol misuse in young people. Cochrane Database of Systematic Reviews 2011, Issue 9. Art. No.: CD009308. DOI: 10.1002/14651858.CD009308. 
Frisher, M., Crome, I., Macleod, J., Bloor, R., Hickman, M. (2007). Predictive factors for illicit drug use among young people: a literature review. UK: Home Office.

Gates, S., McCambridge, J., Smith, L.A. \& Foxcroft, D. (2006). Interventions for prevention of drug use by young people delivered in non-school settings. Cochrane Database of Systematic Reviews 2006, Issue 1. Art. No.: CD005030. DOI:

10.1002/14651858.CD005030.pub2.

Gilligan, C. \& Kypri, K. (2012). Parent attitudes, family dynamics and adolescent drinking: qualitative study of the Australian parenting guidelines for adolescent alcohol use. BMC Public Health, 12, 491.

Griffin, K.W. \& Botvin, G.J. (2010). Evidence-Based Interventions for Preventing Substance Use Disorders in Adolescents. Child and Adolescent Psychiatric Clinics of North America, 19(3), 505-526.

Greene, S. \& Hogan, D. (2005). Researching children’s experiences: methods and approaches. London: Sage.

Hennessy, E. \& Heary, C. (2005). Exploring Children’s Views through Focus Groups. In Greene, S. \& Hogan, D. (eds.), Researching Children’s Experience: Approaches and Methods: Methods and Approaches (2005). London: Sage.

Higgins, K., McCann, M., McLaughlin, A., McCartan, C. \& Perra, O. (2013). Investigating parental monitoring, school and family influences on adolescent alcohol use. Institute of 
Child Care Research, Queen’s University Belfast. End of project report for Alcohol Research UK.

Highet, G. (2005). Alcohol and cannabis: Young people talking about how parents respond to their use of these two drugs. Drugs: Education, Prevention and Policy, 12(2), 113-124.

Hill, L. (2013). ‘Don’t Make Use Talk!’: Listening to and Learning from Children and Young People Living with Parental Alcohol Problems. Children \& Society, 29(5), 344-354, DOI: 10.1111/chso.12064

Hooper. L.M., Doehler, K., Jankowski, P.J. \& Tomek, S.E. (2012). Patterns of self-reported alcohol use, depressive symptoms and body mass index in a family sample: The buffering effects of parentification. The Family Journal: Counselling and Therapy for Couples and Families, 20(2), 164-178.

Hurt, T.R., Brody, G.H. , Murry, V.M., Berkel, C. \& Chen, Y.F. (2013). Elucidating parenting processes that influence adolescent alcohol use: a qualitative inquiry. Journal of Adolescent Research, 1, 28(1), 3-30.

Jacob, N., MacArthur, G.J., Hickman, M. \& Campbell, R. (2015). A qualitative investigation of the role of the family in structuring young people's alcohol use. European Journal of Public Health, 26(1), 102-110. 
Karki, S., Pietilä, A., Länsimies-Antikainen, H., Varjoranta, P., Pirskanen, M. \& Laukkanen, E. (2012). The effects of interventions to prevent substance use among adolescents: a systematic review. Journal of Child \& Adolescent Substance Abuse, 21:383-413.

Krueger, R.A. \& Casey, M.A. (2000). Focus groups: a practical guide for applied research. London: Sage Publications.

Levine, I. S., \& Zimmerman, J. D. (1996). Using qualitative data to inform public policy: Evaluating Choose to De-Fuse. American Journal of Orthopsychiatry, 66(3), 363 -377. Mares, S. H. W., van der Vorst, H., Engels, R., \& Lichtwarck-Aschoff, A. (2011). Parental alcohol use, alcohol-related problems, and alcohol-specific attitudes, alcohol-specific communication, and adolescent excessive alcohol use and alcohol-related problems: An indirect path model. Addictive Behaviors, 36, 209-216.

Mauthner, M. (1997) Methodological aspects of collecting data from children: lessons from three research projects. Children and Society, 11, 16-28.

Miles, M.B. \& Huberman, A.M. (1984). Qualitative data analysis: a source book of new methods. London: Sage.

Morse, J.M. \& Richards, L. (2002). Read Me First for a User’s Guide to Qualitative Methods. Thousand Oaks, CA: Sage Publications. 
Muller, S. \& Kuntsche, E. (2011). Do the drinking motives of adolescents mediate the link between their parents' drinking habits and their own alcohol use? Journal of Studies on Alcohol and Drugs, 72 (3), 429-437.

National Institute on Drug Abuse (2014). High School and Youth Trends.

http://www.drugabuse.gov/sites/default/files/high_school_and_youth_trends_december_2014 .pdf. Accessed 3rd February 2015.

Northern Ireland Statistics and Research Agency (NISRA, 2010). Northern Ireland Multiple Deprivation Measure 2010. Belfast: NISRA.

Oetting, E.R. \& Donnermeyer, J.F. (1998). Primary Socialisation Theory: The Etiology of Drug Use and Deviance. I. Substance Use \& Misuse, 33 (4), 995-1026.

Oman, R. F., Vesely, S., Aspy, C. B., McLeroy, K. R., Rodine, S., \& Marshall, L. D. (2004). The potential protective effect of youth assets on adolescent alcohol and drug use. American Journal of Public Health, 94, 1425-1430.

Panter-Brick, C., Burgess, A., Eggerman, M., McAllister, F., Pruett, K. \& Leckman, J.F. (2014). Practitioner Review: Engaging fathers- recommendations for a game change in parenting interventions based on a systematic review of the global evidence. Journal of Child Psychology and Psychiatry, 55(11), 1187-1212. 
Patrick, M.E., Palen- L-A., Caldwell, L., Gleeson, S., Smith, E. \& Wegner, L. (2010). A qualitative assessment of South African adolescents motivations for and against substance use and sexual behaviour. Journal of Research on Adolescence, 20(2), 456-481.

Peleg-Oren, N., Saint-Jean, G., Cardenas, G.A., Tammara, H. \& Pierre, C. (2009). Drinking Alcohol before Age 13 and Negative Outcomes in Late Adolescence. Alcoholism Clinical and Experimental Research, 33(11), 1966-1972.

Peterson, J. (2010). A Qualitative Comparison of Parent and Adolescent Views Regarding Substance Use. The Journal of School Nursing, 26 (1), 53-64.

Peterson-Sweeney, K. (2005). The use of focus groups in pediatric and adolescent research. Journal of Pediatric Health Care, 19(2), 104-10.

Rew, L., Arheart, K.L., Thompson, S. \& Johnson, K. (2013). Predictors of adolescents’ health-promising behaviors guided by primary socialization theory. Journal for Specialists in Pediatric Nursing, 18 (4), 277-88.

Sarantakos, S. (2005). Social research (3rd ed). Basingstoke: Palgrave Macmillan. Schubotz, D. \& Sinclair, R. (2006). 'Being part and parcel of the schools' The views and experiences of children and young people in relation to the development of bullying policies in schools. London: NCB. 
Scott, J. (2000). Children as Respondents: the Challenge for Quantitative Methods. In. P. Christensen \& A. James (Eds.), Research with Children: Perspectives and Practices (pp. 98119). Great Britain: Falmer Press.

Sherriff, N., Cox, L., Coleman, L. \& Roker, D. (2008). Communication and Supervision of Alcohol in the Family: Parental Perspectives. Children \& Society, 22, 370-382.

Stattin, H. \& Kerr, M. (2009). Challenges in intervention research on adolescent development. Journal of Adolescence, 32, 1437-1442.

Steinberg, L. (2008). Adolescence. New York: McGraw-Hill.

Stephenson, M.T. Quick, B.L., Atkinson, J. \& Tschida, D.A. (2005). Authoritative parenting and drug-prevention practices: implications for antidrug ads for parents. Health Communication, 17(3), 301-21.

Swendsen, J., Burnstein, M., Case, B., Conway, K.P., Dierker, L., He, J. \& Merikangas, K.R. (2012). Use and Abuse of Alcohol and Illicit Drugs in US Adolescents: Results of the National Comorbidity Survey- Adolescent Supplement. Archives of General Psychiatry, 69(4), 390-398.

Templeton, L., Velleman, R. \& Russell, C. (2010). Psychological interventions with families of alcohol misusers: a systematic review. Addiction Research \& Theory, 18(6):616-48. 
Thatcher, D.L. \& Clark, D.B. (2008). Adolescents at Risk for Substance Use Disorders: Role of Psychological Dysregulation, Endophenotypes and Environmental Influences. Alcohol Research \& Health, 31 (2), 168-176.

United Nations (1989). United Nations Convention on the Rights of the Child (UNCRC), Geneva: United Nations.

van der Vorst, H., Engels, R.C.M.E., Meeus, W., Dekovic, M., Vermulst, A. (2006). Parental Attachment, Parental Control, and Early Development of Alcohol Use: A Longitudinal Study. Psychology of Addictive Behaviors, 20 (2), 107-116

Veale, A. (2005). Creative methodologies in participatory research with children. In S. Greene \& D. Hogan (Eds.), Researching Children’s Experiences: Approaches \& Methods (pp. 253-272). London: Sage Publications.

Velleman, R. (2009). Children, young people and alcohol: how they learn and how to prevent excessive use. York: Joseph Rowntree Foundation.

Velleman, R.D.B., Templeton, L.J. \& Copello, A.G. (2005). The role of the family in preventing and intervening with substance use and misuse: a comprehensive review of family interventions, with a focus on young people. Drug and Alcohol Review, 24, 93-109. 
Table 1 Sample characteristics: Age and gender $(\mathrm{N}=62)$

\begin{tabular}{|l|c|c|}
\hline Characteristic & Number & Percentage \\
\hline Gender & & (N) \\
\hline Male & 26 & 41.9 \\
\hline Female & 36 & 58.1 \\
\hline Age & 7 & 11.3 \\
\hline 13 years & 18 & 29 \\
\hline 14 years & 22 & 35.5 \\
\hline 15 years & 11 & 17.7 \\
\hline 16 years & 4 & 6.5 \\
\hline 17 years & & \\
\hline
\end{tabular}


Table 2 Gender and age by focus group (nine groups)

\begin{tabular}{|c|c|c|c|c|}
\hline & Number & $\begin{array}{c}\text { Gender make- } \\
\text { up }\end{array}$ & Age range & Age breakdown \\
\hline \multirow[t]{2}{*}{ Males } & 7 & 7 boys & 15 years & All 15 years \\
\hline & 6 & 6 boys & 13-14 years & $\begin{array}{l}2 \times 13 \text { years } \\
4 \times 14 \text { years }\end{array}$ \\
\hline \multirow[t]{3}{*}{ Females } & 7 & 7 girls & 14-16 years & $\begin{array}{l}3 \times 14 \text { years } \\
1 \times 15 \text { years } \\
3 \times 16 \text { years }\end{array}$ \\
\hline & 8 & 8 girls & 15 years & All 15 years \\
\hline & 6 & 6 girls & 16-17 years & $\begin{array}{l}3 \times 16 \text { years } \\
3 \times 17 \text { years }\end{array}$ \\
\hline \multirow[t]{4}{*}{ Mixed } & 8 & $\begin{array}{l}5 \text { girls } \\
3 \text { boys }\end{array}$ & $14-15$ years & $\begin{array}{l}2 \times 14 \text { years } \\
6 \times 15 \text { years }\end{array}$ \\
\hline & 6 & $\begin{array}{l}3 \text { girls } \\
3 \text { boys }\end{array}$ & 13-14 years & $\begin{array}{l}1 \times 13 \text { years } \\
5 \times 14 \text { years }\end{array}$ \\
\hline & 6 & $\begin{array}{l}4 \text { girls } \\
2 \text { boys }\end{array}$ & 16-17 years & $\begin{array}{l}5 \times 16 \text { years } \\
1 \times 17 \text { years }\end{array}$ \\
\hline & 8 & $\begin{array}{l}3 \text { girls } \\
5 \text { boys }\end{array}$ & 13-14 years & $\begin{array}{l}4 \times 13 \text { years } \\
4 \times 14 \text { years }\end{array}$ \\
\hline
\end{tabular}

